\title{
The impact of healthcare-associated infections on COVID-19 mortality: a cohort study from a Brazilian public hospital
}

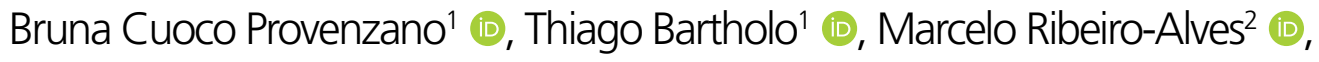 \\ Ana Paula Gomes dos Santos ${ }^{1} \mathbb{1}$, Thiago Thomaz Mafort ${ }^{1}$ (i), Marcos Cesar Santos de Castro ${ }^{1}$ (i), \\ Jose Gustavo Pugliese de Oliveira' (1), Leonardo Palermo Bruno ${ }^{1}$ (1), Agnaldo José Lopes ${ }^{1}$ (1), \\ Claudia Henrique da Costa' (1), Rogerio Rufino ${ }^{1 *}$ (1)
}

\section{SUMMARY}

OBJECTIVE: This study aims to analyze the risk factors for in-hospital mortality in a cohort of patients admitted to a newly adapted intensive care unit in a public hospital in Rio de Janeiro.

METHODS: This was an observational, retrospective, and descriptive study. Data were obtained from electronic medical records. Coronavirus disease 2019 (COVID-19) was diagnosed by detecting viral ribonucleic acid using reverse transcription polymerase chain reaction. Factors associated with the risk/protection from death were determined using the odds ratio and adjusted odds ratio.

RESULTS: Fifty-one patients were admitted to the hospital. The median age of the patients was 63 years, $60 \%$ were male patients, and $54 \%$ were white patients. Sixty-seven percent of the patients were diagnosed with COVID-19. Sepsis at admission increased the chance of in-hospital death by 21 times (adjusted odds ratio=21.06 [0.79-555.2]; $p=0.06$ ). The strongest risk factor for death was the development of septic shock during hospitalization (adjusted odds ratio=98.56 [2.75-352.5]; $p=0.01$ ), and one in four patients had multidrug-resistant bacteria. Mechanical ventilation, vasopressors, neuromuscular blockers, and sedatives were also the risk factors for in-hospital mortality. The in-hospital mortality rate was $41 \%$, and the mortality rate of patients on mechanical ventilation was $60 \%$. The diagnosis of COVID-19 was not statistically related to the adverse outcomes.

CONCLUSIONS: In this cohort, the strongest risk factor for in-hospital death was the development of nosocomial septic shock. Healthcareassociated infections have a significant impact on mortality rates. Therefore, to have a better outcome, it is important to consider not only the availability of beds but also the way healthcare is delivered.

KEYWORDS: SARS-CoV-2. COVID-19. Healthcare associated infection. Mortality. Patient safety.

\section{INTRODUCTION}

In December 2019, the first cases of a new type of pneumonia were identified in Wuhan, Hubei, China. Initially, it was thought to be related with seafood products and the local market. However, in less than 30 days, the viral etiology was established as a new type of coronavirus, the severe acute respiratory syndrome coronavirus 2 (SARS-CoV-2) ${ }^{1}$. From the increasing number of cases, mainly between healthcare professionals, human transmissibility was observed, and the effective reproductive number $(\mathrm{Rt})$ was high ${ }^{2,3}$. Within two months,

\footnotetext{
'Universidade do Estado do Rio de Janeiro, Department of Pneumology and Tisiology - Rio de Janeiro (RJ), Brazil.

${ }^{2}$ Fundação Oswaldo Cruz - Rio de Janeiro (RJ), Brazil.

*Corresponding author: rrufino.uerj@gmail.com

Conflicts of interest: the authors declare there are no conflicts of interest. Funding: none.

Received on May 04, 2021. Accepted on May 30, 2021.
} 
the World Health Organization (WHO) declared coronavirus disease 2019 (COVID-19) a pandemic ${ }^{4}$. In all countries, local healthcare systems were engaged after noting a sudden increase in the number of patients requiring hospitalization ${ }^{5}$.

In Rio de Janeiro, which has a population of approximately 6.72 million people $^{6}$, the number of cases estimated was at least an order of tens of thousands. In May 2020, the Institute for Health Metrics and Evaluation (IMHE) projected that the daily cases would be approximately $30,000^{7}$. Therefore, besides social isolation, one of the adopted strategies to provide more beds to critically ill patients was the conversion of a ward unit in an intensive care facility. In this context, the pneumology ward, from a public tertiary hospital in Rio de Janeiro, Brazil, has become an intensive care unit (ICU) for COVID-19 suspects and confirmed cases. The main goal of this study was to analyze this cohort of patients from the pneumology ward adapted to the ICU to identify the main risk factors for in-hospital mortality in this strategy and the contributing factors that most affected in-hospital mortality.

\section{METHODS}

\section{Study design and population}

This was an observational, retrospective, and descriptive study of a cohort of patients admitted to the newly converted ICU in the Pedro Ernesto University Hospital, Rio de Janeiro, Brazil, from April 25 to June 31, 2020. All patients who met the inclusion criteria were included, and the exclusion criteria included a hospital stay of $<24 \mathrm{~h}$. This study was approved by the National Committee of Ethics and Research (registration number CAAE-30135320.0.0000.5259).

The diagnosis of COVID-19 was made by detecting viral ribonucleic acid (RNA) using reverse transcription polymerase chain reaction (RT-PCR) by collecting samples of nasopharyngeal secretions using swabs. At least two tests were performed in cases of negative or inconclusive results. In the presence of a positive result, the case was considered confirmed.

Sepsis was defined according to the Sepsis 3.0 criteria as when the patient was admitted without sepsis criteria or developed sepsis criteria during hospitalization (after $48 \mathrm{~h})^{8}$.

Data were obtained from electronic medical records. Sociodemographic characteristics such as sex, age, comorbidities, and previous pharmacological, clinical, laboratory, imaging, and therapeutic data gathered during the hospitalization process and clinical evolution until discharge from the unit and hospital were collected.

The description of the cohort of patients was based on their sociodemographic and clinical characteristics. For continuous variables, we used medians, interquartile intervals, and nonparametric
Mann-Whitney U tests. For nominal variables, we used absolute and relative frequency values, and Fisher's exact tests to test the correlation between these variables and the variable death due to the disease at the time of the study. To determine factors associated with risk/protection from death, fixed-effects generalized linear parametric models with a logistic link function (binomial family) were used. The effect's size, the measure of association, was presented as a function of odds ratios adjusted by covariables of confounding $(\mathrm{aOR})$ or not $(\mathrm{OR})$. P-values and confidence intervals of these effects were corrected by the number of comparisons with the reference level using the Holm-Sidak method. All analyses were conducted using the $\mathrm{R}$ version 3.6.3.

\section{RESULTS}

A total of 51 patients were admitted to the hospital. The median patient age was 63 years. Considerably, most of the patients were Caucasian men. More than $70 \%$ of patients had hypertension, and approximately $50 \%$ of these were the users of an angiotensin-converting enzyme inhibitor (ACEI) or angiotensin-receptor blocker (ARB). Previous use of ACEI or ARB was suggested as an in-hospital protection factor for death (aOR=0.091 [0.007-1.221]; $\mathrm{p}=0.07)$. The most prevalent comorbidities in this case series were hypertension $(72.5 \%)$, dyslipidemia (64.7\%), and type 2 diabetes mellitus (37.3\%) (Table 1). Since only four patients did not have comorbidities upon admission, it was not possible to establish an association between these comorbidities and in-hospital death after adjustments for confounding variables. On the contrary, the presence of depression was also considered a risk factor for in-hospital death $(\mathrm{aOR}=1211$ [1.7-2.733]; $\mathrm{p}=0.02)$ (Table 2).

In total, 35 patients were diagnosed with COVID-19, accounting for $67 \%$ of the hospitalized patients. We found no association between SARS-CoV-2 positivity and in-hospital death $(\mathrm{aOR}=0.83$ [0.114-6.082]; $\mathrm{p}=0.85)$. In the subgroup of patients with in-hospital confirmation of COVID-19, approximately 47 had $>50 \%$ radiologic pulmonary involvement. In the subgroup with the SARS-CoV-2-negative swab, four patients presented tomographic features suggestive of viral pneumonia, with involvement between 25 and $50 \%$ of the lung parenchyma.

The presence of sepsis at admission increased the chance of in-hospital death by an average of 21 times $(\mathrm{aOR}=21.06$ [0.79-555.2]; $\mathrm{p}=0.06$ ). In this context, the development of septic shock during hospitalization increased the chance of death by 98 times on an average when compared with those without in-hospital septic shock $(\mathrm{aOR}=98.56$ [2.75-3525]; $\mathrm{p}=0.01)$. This was the highest risk factor for in-hospital mortality.

The presence of multidrug-resistant organisms (MDR) occurred in one of four hospitalized patients, which was considered a risk 
Table 1. Sociodemographic characteristics and their distribution in this population.

\begin{tabular}{|c|c|c|c|c|c|}
\hline & Overall $(n=51)$ & $\begin{array}{c}\text { Survivor } \\
\text { without } \\
\text { COVID-19 } \\
(n=8)\end{array}$ & $\begin{array}{l}\text { Survivor with } \\
\text { COVID-19 } \\
(n=22)\end{array}$ & $\begin{array}{c}\text { Death } \\
\text { without } \\
\text { COVID-19 } \\
(n=8)\end{array}$ & $\begin{array}{c}\text { Death with } \\
\text { COVID-19 } \\
(n=13)\end{array}$ \\
\hline Age & $63(\mathrm{IQR}=16)$ & $56(\mathrm{IQR}=22)$ & $\begin{array}{c}64.5 \\
(I Q R=26.25)\end{array}$ & $67(\mathrm{IQR}=14.75)$ & $65(\mathrm{IQR}=20)$ \\
\hline \multicolumn{6}{|l|}{ Ethnicity (\%) } \\
\hline Caucasian & $28(54.9)$ & $4(7.8)$ & $13(25.5)$ & $4(7.8)$ & $7(13.7)$ \\
\hline Brown & $14(27.5)$ & $3(5.9)$ & $4(7.8)$ & $3(5.9)$ & $4(7.8)$ \\
\hline Afro-Brazilian & $6(11.8)$ & $1(2)$ & $2(3.9)$ & $1(2)$ & $2(3.9)$ \\
\hline Yellow & $3(5.9)$ & $0(0)$ & $3(5.9)$ & $0(0)$ & $0(0)$ \\
\hline \multicolumn{6}{|l|}{ Sex (\%) } \\
\hline Male & $31(60.8)$ & $7(13.7)$ & $12(23.5)$ & $5(9.8)$ & $7(13.7)$ \\
\hline Female & $20(39.2)$ & $1(2)$ & $10(19.6)$ & $3(5.9)$ & $6(11.8)$ \\
\hline BMI & $35(\mathrm{IQR}=4.25)$ & $35(\mathrm{IQR}=0)$ & $33(\mathrm{IQR}=5)$ & $\mathrm{NA}(\mathrm{IQR}=\mathrm{NA})$ & $35(\mathrm{IQR}=0)$ \\
\hline Hypothyroidism (\%) & $2(3.9)$ & $0(0)$ & $0(0)$ & $0(0)$ & $2(3.9)$ \\
\hline Hypertension (\%) & $37(72.5)$ & $4(7.8)$ & $17(33.3)$ & $5(9.8)$ & $11(21.6)$ \\
\hline ACEI/ARB (\%) & $26(51)$ & $4(7.8)$ & $12(23.5)$ & $3(5.9)$ & $7(13.7)$ \\
\hline $\mathrm{T} 2 \mathrm{D}(\%)$ & $19(37.3)$ & $3(5.9)$ & $8(15.7)$ & $2(3.9)$ & $6(11.8)$ \\
\hline Coronary disease (\%) & $14(27.5)$ & $1(2)$ & $6(11.8)$ & $2(3.9)$ & $5(9.8)$ \\
\hline Cardiac failure (\%) & $12(23.5)$ & $1(2)$ & $5(9.8)$ & $2(3.9)$ & $4(7.8)$ \\
\hline Peripheral arterial disease (\%) & $5(9.8)$ & $1(2)$ & $0(0)$ & $2(3.9)$ & $2(3.9)$ \\
\hline Dyslipidemia (\%) & $18(35.3)$ & $1(2)$ & $10(19.6)$ & $2(3.9)$ & $5(9.8)$ \\
\hline CKF without dialysis (\%) & $8(15.7)$ & $1(2)$ & $2(3.9)$ & $2(3.9)$ & $3(5.9)$ \\
\hline CKF with dialysis (\%) & $7(13.7)$ & $1(2)$ & $2(3.9)$ & $3(5.9)$ & $1(2)$ \\
\hline Ischemic cerebral disease (\%) & $4(7.8)$ & $0(0)$ & $1(2)$ & $1(2)$ & $2(3.9)$ \\
\hline Dementia (\%) & $6(11.8)$ & $0(0)$ & $1(2)$ & $2(3.9)$ & $3(5.9)$ \\
\hline Immunosuppressants (\%) & $6(11.8)$ & $0(0)$ & $1(2)$ & $3(5.9)$ & $2(3.9)$ \\
\hline Depression (\%) & $3(5.9)$ & $0(0)$ & $1(2)$ & $0(0)$ & $2(3.9)$ \\
\hline Autoimmune disease (\%) & $3(5.9)$ & $0(0)$ & $1(2)$ & $1(2)$ & $1(2)$ \\
\hline COPD (\%) & $4(7.8)$ & $2(3.9)$ & $2(3.9)$ & $0(0)$ & $0(0)$ \\
\hline Asthma (\%) & $1(2)$ & $0(0)$ & $1(2)$ & $0(0)$ & $0(0)$ \\
\hline Tuberculosis (\%) & $2(3.9)$ & $1(2)$ & $0(0)$ & $0(0)$ & $1(2)$ \\
\hline Tabagism (\%) & $16(31.4)$ & $5(9.8)$ & $4(7.8)$ & $1(2)$ & $6(11.8)$ \\
\hline Cancer (\%) & $6(11.8)$ & $0(0)$ & $1(2)$ & $1(2)$ & $4(7.8)$ \\
\hline
\end{tabular}

Data are expressed as medians and interquartile ranges (IQRs) for continuous data and as absolute (relative) frequencies for categorical data. Percentages may not sum to 100 because of rounding. BMI, body mass index; ACEl: angiotensin-converting-enzyme inhibitor; ARB: angiotensin II receptor blocker; T2D: type 2 diabetes mellitus; CKF: chronic kidney failure; COPD: chronic obstructive pulmonary disease; NA: not available; NC: not computed.

factor for in-hospital death (aOR=14.42 [1.02-204.18]; $\mathrm{p}=0.04)$. Approximately $40 \%$ of the deaths had microbiological evidence of MDR microbes. All hospitalized patients received antibiotic therapy. More than $80 \%$ of the patients received azithromycin, and $47 \%$ of the patients were moved to the carbapenem regimen. Furthermore, the use of vasopressors, sedation, neuromuscular blockers, and corticosteroids was also considered a risk factor for in-hospital mortality. From the laboratory point of view, the last records of leukocytosis and lymphopenia were risk factors for death $(\mathrm{aOR}=25.53$ [2.08-313.48]; $\mathrm{p}=0.06$, and $\mathrm{aOR}=8.76$ [1.42-54]; $\mathrm{p}=0.09$, respectively). Other markers, such as D-dimer, ferritin, lactate dehydrogenase, and total bilirubin, were not associated with mortality. The SOFA score was used, and values above 8 were associated with in-hospital death ( $a \mathrm{OR}=206$ [4.4-9557]; $\mathrm{p}=0.006)$. 
Table 2. Logistic analysis for death during hospitalization.

\begin{tabular}{|c|c|c|c|}
\hline & Overall (\%) & aOR $(95 \% \mathrm{Cl})^{\mathrm{a}}$ & p-value \\
\hline SARS-CoV-2 positive & $35(68.6)$ & $0.83(0.11-6.08)$ & 0.85 \\
\hline SOFA admission & $4(\mathrm{IQR}=4)$ & $1.36(0.11-16)$ & 0.80 \\
\hline In-hospital SOFA & $8(\mathrm{IQR}=7.5)$ & $206(4.48-9557)$ & 0.006 \\
\hline Septic shock in admission & $8(15.7)$ & $21(0.79-555)$ & 0.06 \\
\hline Septic shock in hospital & $17(33.3)$ & $98(2.75-3525)$ & 0.01 \\
\hline Vasopressors & $27(52.9)$ & $69.66(1.76-2733)$ & 0.02 \\
\hline Inotropic & $4(7.8)$ & $0.148(0.001-24.17)$ & 0.46 \\
\hline Sedation & $30(58.8)$ & 69 (1.77-2733) & 0.03 \\
\hline Benzodiazepine & $28(54.9)$ & $70(1.8-2763)$ & 0.02 \\
\hline Neuromuscular blocker & $17(33.3)$ & $126(3.73-4277)$ & 0.007 \\
\hline Corticoid & $27(52.9)$ & $50(2.2-1136)$ & 0.01 \\
\hline Chloroquine & $15(29.4)$ & $0.4(0.017-9.71)$ & 0.57 \\
\hline Oseltamivir & $22(43.1)$ & $3.4(0.37-32)$ & 0.27 \\
\hline Carbapenems & $24(47.1)$ & $3.8(0.46-32)$ & 0.21 \\
\hline Betalactamic & $25(49)$ & $3.3(0.4-26)$ & 0.26 \\
\hline Cephalosporin & $24(47.1)$ & $0.53(0.05-4.91)$ & 0.58 \\
\hline Glycylcycline & $3(5.9)$ & $2.6(0.05-134)$ & 0.63 \\
\hline Macrolide & $41(80.4)$ & $3.65(0.36-37$ & 0.27 \\
\hline Glycopeptide & $20(39.2)$ & $8.75(0.66-109)$ & 0.09 \\
\hline Polymyxins & $10(19.6)$ & $25.42(0.79-814)$ & 0.06 \\
\hline Quinolone & $10(19.6)$ & $10.6(0.51-220)$ & 0.12 \\
\hline Antifungals & $7(13.7)$ & $9.63(0.36-255)$ & 0.17 \\
\hline Prophylactic enoxaparin & $20(39.2)$ & $1.119(0.11-10)$ & 0.92 \\
\hline Anticoagulation & $39(76.5)$ & $0.343(0.04-2.92)$ & 0.32 \\
\hline Dialysis & $16(31.4)$ & $4.39(0.481-40.13)$ & 0.18 \\
\hline MDR bacteria & $16(31.4)$ & $14(1.02-204)$ & 0.04 \\
\hline Nasal catheter & $29(56.9)$ & $0.11(0.01-0.92)$ & 0.04 \\
\hline NIMV & $1(2)$ & $\mathrm{NC}$ & $\mathrm{NC}$ \\
\hline IMV & $28(54.9)$ & $70(1.8-2763)$ & 0.02 \\
\hline Days in IMV & $2(\mathrm{IQR}=9)$ & $89(1.4-5614)$ & 0.03 \\
\hline Auto prone & $12(23.5)$ & $1.67(0.11-24)$ & 0.7 \\
\hline ARDS & $12(23.5)$ & $25(0.814-654)$ & 0.06 \\
\hline In-hospital stay & $17(\mathrm{IQR}=17.75)$ & $0.31(0.053-1.82)$ & 0.55 \\
\hline In ICU stay & $9(\mathrm{IQR}=10)$ & $1.82(0.28-11.65)$ & 0.52 \\
\hline
\end{tabular}

aOdds ratios were adjusted for confounding variables ("Septic Shock Admission," “Peripheral Arterial Disease," "Dementia," "Immunosuppressants," "Cancer," "Urea Admission value," "DHL Admission value," "SOFA Admission value," and "BMI"), which were considered at least suggestive by bivariate analyzes and were present before the study. SARS-CoV-2: severe acute respiratory syndrome coronavirus 2; SOFA: sequential organ failure assessment; MDR: multidrug resistant; NIMV: non-invasive mechanical ventilation; IMV: invasive mechanical ventilation; ARDS: acute respiratory distress syndrome; ICU: intensive care unit.

The use of invasive mechanical ventilation (IMV) was also a risk factor for in-hospital death $(\mathrm{aOR}=70.5[1.8-2763.9]$; $\mathrm{p}=0.02$ ). About $60 \%$ of the patients who underwent IMV resulted in death. Being on IMV for $>2$ days was enough to find an association with in-hospital death $(\mathrm{aOR}=89$ [1.4-5614.2]; $\mathrm{p}=0.03)$. Since only one patient received non-invasive mechanical ventilation (NIMV) support, it was not possible to establish a statistical relationship with in-hospital outcomes. In parallel, the use of a nasal oxygen catheter was a protective factor against in-hospital death $(\mathrm{OR}=0.1[0.01-0.92] ; \mathrm{p}=0.04)$. In addition, 
approximately $33 \%$ of patients developed renal dysfunction and required hemodialysis. However, no association was found between dialysis support and in-hospital death $(\mathrm{aOR}=4.39$ [0.48-40.13]; $\mathrm{p}=0.18$ ). In total, the in-hospital mortality rate was $41 \%$, and the mortality rate of patients with IMV was $60 \%$.

\section{DISCUSSION}

This study is the first to analyze the strategy of converting ward units into an ICU, as a solution to the deficit in intensive care beds in the face of the pandemic. Through data collection and careful statistical analysis, it was possible to identify the factors that contributed to in-hospital mortality. Furthermore, this allowed us to understand the function and approach of this strategy.

The COVID-19 pandemic caused a significant increase in the number of patients requiring hospitalization and intensive care. Based on this demand, a contingency plan was needed to receive these patients ${ }^{9}$. For example, the strategy of adapting a hospital unit exists for another purpose in an $\mathrm{ICU}^{10}$. The quality of intensive care in developing countries was recognized as a challenge ${ }^{11}$, which did not arise with the pandemic but as evidenced by $\mathrm{it}^{12}$. Undoubtedly, it was necessary to increase the supply of intensive care beds. In Rio de Janeiro, the deficit of beds was already known in the public Brazilian healthcare system, which is responsible for serving most of the population. The ratio of ICU beds per 10 thousand inhabitants in Rio de Janeiro is 0.97; the WHO recommended one to three beds per 10 thousand inhabitants (in a context outside the pandemic) ${ }^{13}$. Furthermore, in addition to the availability of beds, the manner of healthcare delivery for critical care patients was also important ${ }^{14}$.

In this cohort, the most evident risk factor for in-hospital mortality was the development of in-hospital septic shock. Hence, for patients who did not meet the sepsis criteria but developed during hospitalization, an infection and septic shock of probable nosocomial origin increased the probability of mortality by 98 times as compared to those who did not manifest similar conditions.

The use of ventilatory support was recurrent, with more than $50 \%$ of patients progressing to IMV. In other retrospective analyses, this percentage varied from $13-31 \%{ }^{15,16}$. Furthermore, the mortality of these patients ranged from $24.5-76.5 \%{ }^{17}$. In this study, the mortality rate for the subgroup of patients with COVID-19 who required IMV was 60\%.

Only $67 \%$ of patients had a positive nasal swab for SARS$\mathrm{CoV}-2$. In total, $25 \%$ of patients who had negative results had images suggestive of viral pneumonia. In this case series, the quantitative method of detecting genetic material by RT-PCR was used, as recommended by the $\mathrm{WHO}^{17}$. The sensitivity of this method varied between $53.6-73.3 \%$, according to the previous meta-analyses performed ${ }^{18}$. To optimize the sensitivity of the diagnosis, serial tests were performed, and tests with different methodologies were used to detect patients with suggestive tomographic changes, despite the negative admission test ${ }^{19}$. Interestingly, the diagnosis of COVID-19 was not a risk factor for in-hospital mortality, corroborating the impact of nosocomial infections on the outcome of these patients.

This study had limitations owing to its design and the number of participants. Hence, it was not possible to establish the cause and consequences. The beneficial or harmful effects of treatment cannot be listed for this number of patients. However, results revealed relevant issues regarding the organizational strategy, as represented by the impact that in-hospital infections had on the mortality of patients hospitalized because of confirmed or suspected COVID-19. These infections were probably associated with healthcare measures and were potentially preventable. Moreover, this study highlighted that this was a window of opportunity to work on strategies, such as educational programs, to apply proven protocols and checklists that could improve the quality of care ${ }^{19}$.

\section{CONCLUSIONS}

The pandemic has challenged healthcare systems worldwide to adapt to a sudden increase in the number of patients. The transformation of a ward into an ICU was one of the strategies employed, thereby allowing a quick and necessary response. Nevertheless, the creation of an ICU is complex, and several challenges need to be overcome. Much is discussed about drug therapies and invasive devices of high cost and technology. However, more organizational measures of safety and quality would allow better in-hospital outcomes, making it a cost-effective strategy to optimize the care of critically ill patients.

The method of responding to the increase in cases in the Brazilian health system was much more in order to increase the number of beds than to reduce the number of cases. The effect of this policy ended in the creation of units with improvised structures and had an important impact on the mortality of admitted patients.

\section{ACKNOWLEDGMENTS}

The authors thank the Director and Vice-Director of the Pedro Ernesto University Hospital and all members of Pulmonology Discipline of Medical Sciences Faculty/Rio de Janeiro State University.

\section{AUTHORS" CONTRIBUTIONS}

BCP: Conceptualization, Data curation, Formal Analysis, Investigation, Methodology, Writing - original draft. TB: Conceptualization, Data curation, Formal 
Analysis, Methodology, Writing - review \& editing. AJL: Conceptualization. CHC: Conceptualization, Investigation.

RR: Conceptualization, Formal Analysis, Methodology, Project administration, Supervision, Writing - original draft,
Writing - review \& editing. APGS: Investigation. TTM: Investigation. MCSC: Investigation. JGP: Investigation. LPB: Investigation. MRA: Formal Analysis, Methodology, Writing - original draft.

\section{REFERENCES}

1. Zhu N, Zhang D, Wang W, Li X, Yang B, Song J, et al. A novel coronavirus from patients with pneumonia in China, 2019. N Engl J Med. 2020;382(8):727-33. https://doi.org/10.1056/NEJMoa2001017

2. Shereen MA, Khan S, Kazmi A, Bashir N, Siddique R. COVID-19 infection: origin, transmission, and characteristics of human coronaviruses. J Adv Res. 2020;24:91-8. https:// doi.org/10.1016/j.jare.2020.03.005

3. Chu DK, AkI EA, Duda S, Solo K, Yaacoub S, Schünemann HJ, et al. Physical distancing, face masks, and eye protection to prevent personto-person transmission of SARS-CoV-2 and COVID-19: a systematic review and meta-analysis. Lancet. 2020;395(10242):1973-87. https://doi.org/10.1016/S0140-6736(20)31142-9

4. World Health Organization. Listings of WHO's response to COVID-19. Geneva: World Health Organization; 2021. [cited on Oct. 14, 2020]. Available from: https://www.who.int/ news-room/detail/29-06-2020-covidtimeline

5. Gilardino RE. Does "flattening the curve" affect critical care services delivery for COVID-19? A global health perspective. Int J Health Policy Manag. 2020;9(12):503-7. https://doi. org/10.34172/ijhpm.2020.117

6. Instituto Brasileiro de Geografia e Estatística. Estimativas da população residente no brasil e unidades da federação com data de referência em $1^{\circ}$ de julho de 2019. 2019. [cited on Oct. 14, 2020]. Available from: https:// agenciadenoticias.ibge.gov.br/media/com_mediaibge/ arquivos/7d410669a4ae85faf4e8c3a0a0c649c7.pdf

7. Institute for Health Metrics and Evaluation. COVID-19 projections. 2020. [cited on Oct. 14, 2020]. Available from: https://covid19.healthdata.org/brazil/rio-de-janeiro

8. Singer $M$, Deutschman CS, Seymour CW, Shankar-Hari $M$, Annane D, Bauer $M$, et al. The third international consensus definitions for sepsis and septic shock (sepsis-3). JAMA. 2016;315(8):801-10. https://doi.org/10.1001/jama.2016.0287

9. Aziz S, Arabi YM, Alhazzani W, Evans L, Citerio G, Fischkoff $\mathrm{K}$, et al. Managing ICU surge during the COVID-19 crisis: rapid guidelines. Intensive Care Med. 2020;46(7):1303-25. https://doi.org/10.1007/s00134-020-06092-5

10. [10] Peters AW, Chawla KS, Turnbull ZA. Transforming ORs into ICUs. N Engl J Med. 2020;382(19):e52. https://doi. org/10.1056/NEJMc2010853
11. Machado FR, Ferreira EM, Sousa JL, Silva C, Schippers $P$, Pereira A, et al. Quality Improvement Initiatives in Sepsis in an Emerging Country: Does the Institution's Main Source of Income Influence the Results? An Analysis of 21,103 Patients. Crit Care Med. 2017;45(10):1650-9. https://doi.org/10.1097/ CCM.0000000000002585

12. Salluh JIF, Lisboa T, Bozza FA. Challenges for the care delivery for critically ill COVID-19 patients in developing countries: the Brazilian perspective. Crit Care. 2020;24(1):593. https://doi. org/10.1186/s13054-020-03278-7

13. Palamim CVC, Marson FAL. COVID-19 - the availability of ICU beds in Brazil during the onset of pandemic. Ann Glob Health. 2020;86(1):100. https://doi.org/10.5334/aogh.3025

14. Conde KA, Silva E, Silva CO, Ferreira E, Freitas FG, Castro I, et al. Differences in sepsis treatment and outcomes between public and private hospitals in Brazil: a multicenter observational study. PLoS One. 2013;8(6):e64790. https://doi.org/10.1371/ journal.pone.0064790

15. Grasselli G, Greco M, Zanella A, Albano G, Antonelli M, Bellani $G$, et al. Risk factors associated with mortality among patients with COVID-19 in intensive care units in Lombardy, Italy. JAMA Intern Med. 2020;180(10):1345-55. https://doi. org/10.1001/jamainternmed.2020.3539

16. Richardson S, Hirsch JS, Narasimhan M, Crawford JM, McGinn T, Davidson KW, et al. Presenting characteristics, comorbidities, and outcomes among 5700 patients hospitalized with COVID-19 in the New York City area. JAMA. 2020;323(20):2052-9. https://doi.org/10.1001/jama.2020.6775

17. McFee DRB. COVID-19 medical management including World Health Organization (WHO) suggested management strategies. Dis Mon. 2020;66(9):101068. https://doi.org/10.1016/j. disamonth.2020.101068

18. Li C, Ren L. Recent progress on the diagnosis of 2019 Novel coronavirus. Transbound Emerg Dis. 2020;67(4):1485-91. https://doi.org/10.1111/tbed.13620

19. Haniffa R, Silva AP, Azevedo L, Baranage D, Rashan A, Baelani I, et al. Improving ICU services in resource-limited settings: perceptions of ICU workers from low-middle-, and highincome countries. J Crit Care. 2018;44:352-6. https://doi. org/10.1016/j.jcrc.2017.12.007 